\title{
Bilateral Chylothorax due to Disseminated Tuberculosis and Acute Lymphoblastic Leukemia in a young boy : A case report and Literature review
}

\author{
SAYEEDAANWAR ${ }^{1}$, A.K.M. MATIUR RAHMAN ${ }^{2}$, M. EKHLASUR RAHMAN ${ }^{3}$, MD. ABID HOSSAIN \\ MOLLAH $^{4}$, ABDUL MATIN $^{5}$, LAILA BILQIS 6
}

\section{Introduction}

Chylothorax is a rare condition that results from thoracic duct damage with chyle leakage, characterized by high triglyceride and low cholesterol concentrations, from the lymphatic system into the pleural space. Thoracic duct may be obstructed or ruptured producing sometimes bursting of lymph vessels. ${ }^{1}$ This is manifested by the collection of chylous fluid in the pleural and peritoneal sacs, chylous hydrocele and chylous urine. Chylothorax was recognized in the $17^{\text {th }}$ century at first. Joshman and Bartolet ${ }^{4}$ described chylothorax initially in 1633 and Quincke reported the first case in 1875 . The commonest etiology is malignancy and trauma to the thoracic duct.$^{1}$ Diagnosis involves cholesterol and triglyceride measurement in the pleural fluid. Complications include malnutrition, immunosuppression and respiratory distress. Treatment may be either conservative or aggressive depending on the clinical scenario.

Chylothorax is infrequently associated with lymphoma, but association with acute lymphoblastic leukemia is rare. $^{2}$ The development of bilateral chylothorax due to tuberculosis is also very uncommon. ${ }^{3}$

We report a case of bilateral chylothorax in a young boy due to disseminated tuberculosis not only because of rare condition, but also for unsupported association of acute lymphoblastic leukemia. And also keeping in mind that chylothorax may occur due to leukemia and tuberculosis.

1. Associate Professor, Department of Pediatrics, Dhaka Medical College Hospital, Dhaka.

2. Assistant Professor, Department of Pediatrics, Dhaka Medical College Hospital, Dhaka.

3. Professor and Head of the Department, Department of Pediatrics, Dhaka Medical College Hospital, Dhaka.

4. Professor, Department of Pediatrics, Dhaka Medical College Hospital, Dhaka.

5. Assistant Professor, Department of Pediatrics, Dhaka Medical College Hospital, Dhaka.

6. Trainee Doctor, Department of Pediatrics, Dhaka Medical College Hospital, Dhaka.

Correspondence: Dr. Sayeeda Anwar

\section{Case report}

A 9-year-old immunized boy presented with low grade fever for 2 months, swelling of the face and upper chest for 2 months and difficulty in breathing for last $1 \frac{1 / 2}{2}$ months. He came from Sunamgonj, a nonendemic zone of Filariasis. He had history of close contact with tubercular patient (open case). With above complaints, he was at first admitted into a tertiary care hospital outside Dhaka and was treated with broad spectrum antibiotics and steroid for 2 weeks. But he did not improve and he was referred to Dhaka Medical College hospital. Clinically, he was underweight (BMI $11.7 \mathrm{~kg} / \mathrm{m}^{2}$, i.e, $<3^{\text {rd }}$ centile for age and sex), moderately pale and febrile, he had fast breathing. Lymph nodes were not palpable. There was redness and fullness as well as restricted movement of the chest more on left side. Trachea was shifted to the right side. Vocal fremitus and vocal resonance were absent on left side and diminished on right side. Percussion note was dull on left side and lower part of the right side. Breath sound was absent on left side and lower part of the right side. Other systemic examinations revealed normal.

Some investigations were done. Initially two blood counts were done at 4 weeks interval both showing normal total and differential leukocyte counts with low hemoglobin level $(6.9 \mathrm{~g} / \mathrm{dl}$ and $7.8 \mathrm{~g} / \mathrm{dl})$. Chest X-ray showed bilateral pleural effusion [Figure 1]. The pleural fluid was aspirated. Color was milky white. Total cell count was $800 / \mathrm{mm}^{3}$, degenerated neutrophil was $10 \%$, lymphocyte was $90 \%$. Triglyceride was high (271 $\mathrm{mg} / \mathrm{dl}$ ). There was no growth in Gram staining, no AFB was found, no growth in $\mathrm{C} / \mathrm{S}$. Pleural fluid for ADA was high (45.3 U/L) [Table 1]. S. LDH was normal. Serum Lipid profile showed high cholesterol (298 mg/ dl). S. electrolyte, S. creatinine, S. albumin were normal. Anti TB IgG was normal. IGRA (3-INF regeneration assay) was negative. After drainage of pleural fluid from left side, CT scan of chest showed bilateral pleural effusion more in right lung [Figure 3]. CT scan of whole abdomen was normal.

Thus the case was diagnosed as bilateral chylothorax due to disseminated tuberculosis. 
Table-I

Characteristics of the pleural fluid

\begin{tabular}{ll}
\hline Pleural fluid & Characteristics \\
\hline Color & milky white \\
Protein & $4.5 \mathrm{~g} / \mathrm{dl}$ \\
Sugar & $48 \mathrm{mg} / \mathrm{dl}$ \\
Total cell count & $800 / \mathrm{mm}^{3}$ \\
Differential count & Neutrophil 10\% lymphocyte 90\% \\
Triglyceride & $271 \mathrm{mg} / \mathrm{dl}$ \\
Cholesterol & $11 \mathrm{mg} / \mathrm{dl}$ \\
Culture and sensitivity & Sterile \\
ADA & $45.3 \mathrm{U} / \mathrm{L}$ \\
\hline
\end{tabular}

To confirm the exact site of damage of the thoracic duct, lymphangiography was advised. But this facility is not yet available in our country.

The patient was put on continuous water seal drainage. Dietary modification was given with medium chain triglycerides (coconut oil and olive oil rich diet). He was treated by broad spectrum antibiotics, antitubercular therapy with steroid and breathing exercise. Chylothorax resolved completely after above treatment of 6 weeks more evidenced by radiological improvement [Figure 3].

After 6 weeks, on repeat differential leukocyte count showed $74 \%$ blast cell and peripheral blood film was suggestive of acute lymphoblastic leukemia. Serum $\mathrm{LDH}$ was high (840 U/L). Bone marrow examination revealed acute lymphoblastic leukemia.

On regular follow up, he was well and had no further complains and then he was referred to Pediatric HematoOncology Department for further management.

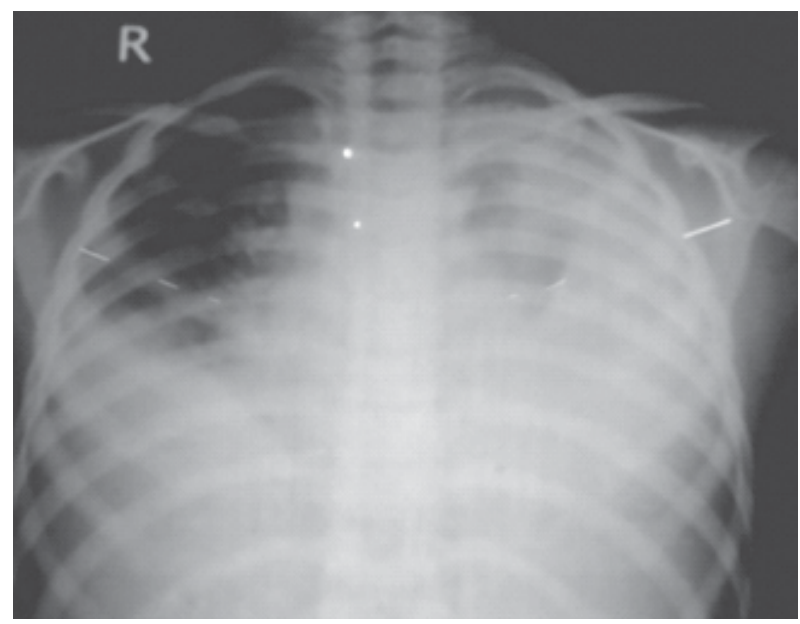

Fig.-1: Chest $X$-ray showing bilateral pleural effusion more on left side

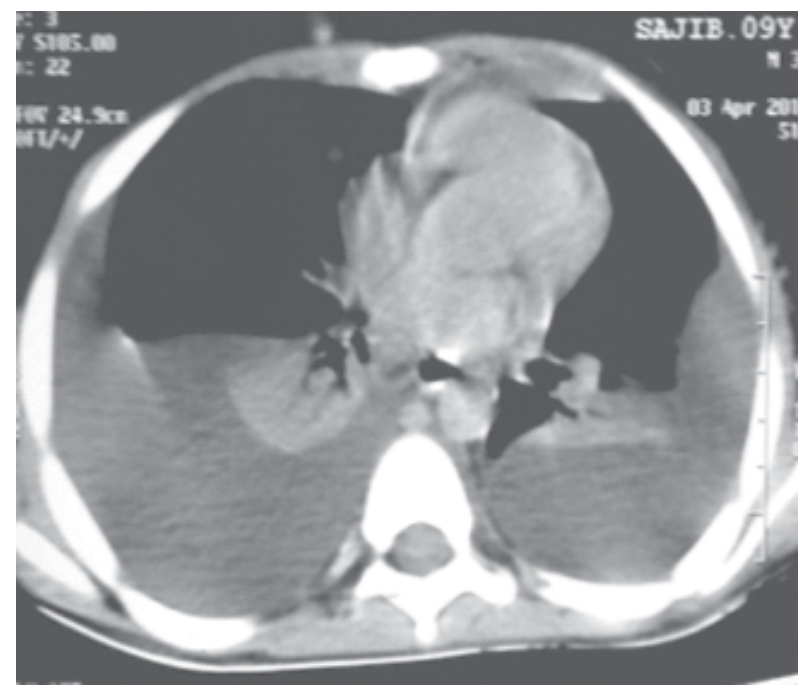

Fig.-2: CT scan of chest showing bilateral pleural effusion

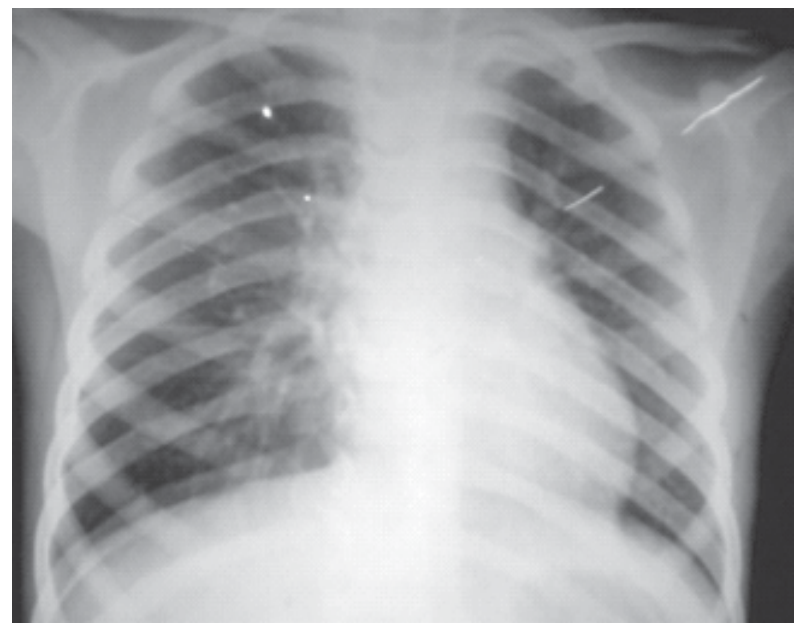

Fig.-3: Radiological clearing of bilateral pleural effusion after anti-TB therapy

\section{Discussion}

Chylothorax is defined as the accumulation of chylecontaining lymphatic fluid resulting from obstruction or disruption of the thoracic duct. Chylothorax usually develop as the result of extrinsic compression or direct invasion of the thoracic duct by a tumor or as the result of obliteration of the lymphatics following radiation therapy. ${ }^{4,5}$ An extrinsic obstruction or an infiltration of the thoracic duct causes an increase in back pressure. This elevated pressure promotes dilatation of collateral channels and renders lymphatic valves incompetent, which produces regurgitant flow of chyle. Consequently, seepage may occur through erosion or perforation of a diseased thoracic duct or one of its tributaries into the mediastinum. Mediastinal chyle then penetrates the mediastinal pleura, 
producing a chylothorax; alternatively, leakage may occur directly into the pleural space from the dilated intrapulmonary lymphatics because of the regurgitant flow from the bronchomediastinal trunk or posterior intercostal lymphatics. ${ }^{4,5}$

Sassion et $\mathrm{al}^{2}$ divided the causes of chylothorax into four major categories: tumour, trauma, idiopathic, and miscellaneous. Malignancy accounted for approximately one half; lymphoma being the most common malignancy (almost 75\%) followed by bronchogenic carcinoma. 5,6 Trauma is the leading cause of chylothorax. Traumatic cases can be further sub-classified as iatrogenic or non-iatrogenic (20\% of traumatic cases) with rupture even described after coughing or vomiting episodes. ${ }^{1,7}$ Thoracic surgery has now replaced physical injury as the leading cause of trauma with oesophageal surgery having an incidence of $4 \% .{ }^{8}$ Non-traumatic etiologies include malignancy, sarcoidosis, retrosternal goitre, amyloidosis, Gorhams syndrome , ${ }^{9}$ Kaposi sarcoma, 10,11 Castleman disease, ${ }^{12}$ superior vena cava thrombosis, benign tumours, congenital duct abnormalities and diseases of the lymph vessels such as yellow nail syndrome and haemagiomatosis. ${ }^{1}$ Thoracic duct obstruction due to malignancy is the commonest cause of non-traumatic chylothorax. Lymphoma is found in $70 \%$ of cases (nonHodgkin's $>$ Hodgkin's). ${ }^{8}$ Rarely metastatic tumour can give rise to duct obstruction. ${ }^{1}$ Disease of the lymph vessels is extremely uncommon. Malignancy is a leading cause of chylothorax. The most common malignancy to cause chylothorax is a lymphoma, 5,13 followed by bronchogenic carcinoma $4,14,15,16,17,18,19$ and rarely leukemia. ${ }^{2}$

Very few cases of chylothorax secondary to acute lymphoblastic leukemia are reported. 2,20,21 In our country this is the first reported case of chylothorax associated with acute lymphoblastic leukemia and disseminated tuberculosis. In our case, there was a positive history of close contact with tubercular open case. Though there were no lymph nodes palpable, may be because of getting steroids for 2 weeks. High pleural fluid ADA (cut off value $>40 \mathrm{U} / \mathrm{L}$ ) ${ }^{15}$ helped to reach for diagnosis of tuberculosis.

Tuberculosis is described as a possible cause of chylothorax. ${ }^{9}$ The exact pathogenesis for the development of chylothorax secondary to tuberculosis remains controversial. Fraser et al. ${ }^{22}$ and Yunis et al. ${ }^{23}$ reported that the enlarged lumber and iliac group of lymph nodes produced obstruction of the cisterna chyli and thoracic duct, as a result of which there was dilatation of the lumbar channels; this was followed by the opening up of collateral anastomoses, many lymphaticovenous anastomoses existing between the thoracic duct system and the azygos, intercostal, and lumbar veins. The increased pressure in the system resulted in the transudation of chyle into the pleural space. Grobbelaar et al. reported that the possible explanation for the development of a chylothorax in our patients is the obstruction of the thoracic duct by tuberculous lymphadenopathy with subsequent increase in pressure in the surrounding lymphatic system and leaking of chyle into the pleural space. ${ }^{24}$

Staats et al. introduced criteria for the biochemical diagnosis of chylothorax in $1980 .{ }^{25}$ Best way to establish the diagnosis of chylothorax is to determine the concentration of triglycerides in the pleural fluid. The triglyceride concentration greater than $110 \mathrm{mg} / \mathrm{dl}$ 25 (in our case it was $271 \mathrm{mg} / \mathrm{dl}$ ), a ratio of pleural fluid to serum triglycerides of greater than $1.0^{7}$ (in our case it was 1.58), and a ratio of pleural fluid to serum cholesterol of less than $1.0^{7}$ (in our case it was 0.07 ) usually confirm chylothorax. Chylothorax will be excluded if the pleural fluid triglyceride concentration is less than $50 \mathrm{mg} / \mathrm{dl}^{25}$ However, in the case of levels from 50 to $110 \mathrm{mg} / \mathrm{dl}$, a lipoprotein analysis of the pleural fluid should be performed, and the demonstration of chylomicrons in the fluid confirms the diagnosis of chylothorax [Table-II]. ${ }^{4}$

Table-II

Pleural fluid criteria for the diagnosis of chylothorax and pseudochylothorax

\begin{tabular}{lcccc}
\hline & Triglyceride & Cholesterol & Chylomicron & $\begin{array}{c}\text { Cholesterol } \\
\text { crystal }\end{array}$ \\
\hline Chylothorax & $110 \mathrm{mg} / \mathrm{dl}$ & $200 \mathrm{mg} / \mathrm{dl}$ & Present & Not seen \\
Pseudochylothorax & $50 \mathrm{mg} / \mathrm{dl}$ & $200 \mathrm{mg} / \mathrm{dl}$ & Absent & Often seen \\
\hline
\end{tabular}


Treatment can be classified under 3 categories $^{26}$ treatment of the underlying condition, ${ }^{1}$ conservative management ${ }^{7}$ and surgical management. ${ }^{1}$ But treatment of the underlying condition may lead to improvement in the disease burden (e.g. Iymphoma) without necessarily improving the chylothorax. ${ }^{27}$ Conservative management is to correct malnutrition and compromised immunologic status which is due to repeated pleural fluid aspirations of chyle with its high levels of protein, fat, electrolytes, and lymphocytes. ${ }^{28}$ The defect in the thoracic duct often closes spontaneously in the case of traumatic injury. In the case of severe dyspnea, the placement of the pleuroperitoneal shunt or chest tube drainage is mandatory. ${ }^{4}$ If the chylothorax persists for more than 4 weeks, consideration should be given to surgical exploration with ligation of the thoracic duct. ${ }^{29}$

In our case, diagnosis of chylothorax was established on typical pleural fluid color, high pleural fluid triglyceride level, high ratio of pleural fluid to serum triglyceride, and low ratio of pleural fluid to serum cholesterol. He did not need surgical exploration, but responded well to medical treatment like continuous drainage of pleural fluid, dietary modification with medium chain triglyceride and then referred for chemotherapy for acute lymphoblastic leukemia.

\section{Conclusion}

Patients with hematologic malignancies may occasionally acquire pleural effusions due to lymphatic obstruction, disease extension or infections. We should remember while treating any patient with chylothorax, the probable diagnosis may be malignancy and also tuberculosis. Clinical scenario, history of contact, pleural fluid cytology and other biochemical profiles should be considered to establish the diagnosis. Treatment of the primary disease usually improves chylothorax.

\section{References}

1. Hillerdal G. Chylothorax and pseudochylothorax. Eur Respir J 1997;10:1157-62.

2. Menon BS, Juraida E, Mahfuzah M, et al. Bilateral chylothorax in paediatric acute lymphoblastic leukaemia. $\mathrm{Br} \mathrm{J}$ Haematol. 2006;132: 253.

3. Anton PA, Rubio J, Casan P, Franquet $\mathrm{T}$. Chylothorax due to Mycobacterium tuberculosis. Thorax. 1995;50:1019.
4. Valentine VG, Raffin TA. The management of chylothorax. Chest 1992;102:586-591.

5. Doers CH, Miller DL, Ryu JH. Chylothorax. Semin Respir Crit Care Med. 2001;22:617-26.

6. Sassoon CS, Light RW. Chylothorax and pseudochylothorax. Clin Chest Med. 1985;6: 163-71.

7. Nair SK, Petko M, Hayward MP. Aetiology and management of chylothorax in adults. Eur J Cardiothorac Surg 2007;32(2):

8. McWilliams A, Gabbay E. Chylothorax occurring 23 years postirradiation: literature review and management strategies. Respirology 2000; 5: 301-3.

9. Johnston RF, Dovnasky JH. Pleural diseases. In: Fishman AP, editor. Pulmonary diseases and disorders. New York: McGraw-Hill' Co; 1980. p. 1370.

10. Duffy BM, Manon R, Patel RR, Welsh JS. Chylothorax in a patient of HIV and Kaposis sarcoma. Clin Med Res. 2005;3:83-6.

11. Marais BJ, Pienaar J, Gie RP. Kaposi sarcoma with upper airway obstruction and bilateral chylothoraces. Pediatr Infect Dis J. 2003; 22: 926-8.

12. Blankenship ME, Rowlett J, Timby JW, Roth RS, Robert E, Jones RE. Giant Lymph Node Hyperplasia (Castleman's Disease) Presenting With Chylous Pleural Effusion. Chest. 1997;112:1132-3.

13. Elburjo M, Darrat A, Mahdawi A, Ghada Ali. Chylothorax in Nonhodgkin Lymphoma Treated By Left Cervical Lymphadenoidectomy. Internet J Thorac Cardiovasc Surg. 2005;7:11.

14. Arora VK, Bedi RS. Chylothorax complicating bronchogenic carcinoma. Indian J Chest Dis Allied Sci. 1986;28:92-4.

15. Jindal SK, Malik SK, Malik AK, Sinoh K, Gujral JS, Sodhi JS. Bronchogenic carcinoma a review of 150 cases. Indian J Chest Dis Allied Sci. 1979;21:59-64. [PubMed]

16. Basu AK. Carcinoma of the lung. Indian J Chest Dis Allied Sci. 1962;24:82.

17. Guleria JS, Gopinath N, Talwar JR, Bhargava S, Pande JN, Gupta GR. Bronchial carcinoma An 
analysis of 120 cases. J Assoc Physicians India. 1971;19:251-5. [PubMed]

18. Jha VK, Roy DC, Ravindran p. Bronchogenic carcinoma a clinicopathological study. Indian J Chest Dis Allied Sci. 1972;14:78-85.

19. Narang PK, Dubey AL, Gupta MC, Raju S. Primary bronchogenic carcinoma-a clinical study. Indian J Chest Dis Allied Sci. 1977;19:120-3.

20. Khattab T, Smith S, Barbor P, Ghamdi SA, Abbas A, Fryer $C$. Extramedullary relapse in a child with mixed lineage acute lymphoblastic leukemia: Chylous pleuropericardial effusion. Med Pediatr Oncol. 2000;34:274-5.

21. Kushwaha RAS, Prasad R, Verma SK, Mehra S. Bilateral Chylothorax secondary to acute lymphoblastic leukemia (ALL) Indian J Med Paediatr Oncol. 2007;28:42 - 3.

22. Fraser RG, Part JA. Diagnosis of diseases of the chest. In: Fraser RG, Part JA, editors.
Diagnosis of diseases of the chest. Philadelphia: WB. Saunders Co; 1979. pp. 1769-70.

23. Yunis EJ, Moran TJ. Chylothorax and portal cirrhosis. JAMA. 1965; 192: 250-1.

24. Grobbelaar M, Andronikou S, Goussard P, Theron S, Mapukata A, George R. Chylothorax as a complication of pulmonary tuberculosis in children. Pediatr Radiol. 2008; 38: 224-6.

25. Staats BA, et al. The lipoprotein profile of chylous and non-chylous pleural effusions. Mayo Clin Proc 1980; 55: 700 - 4.

26. Macfarlane JR, Holman CW. Chylothorax. Am Rev Respir Dis 1972;105(2): 287 - 91.

27. O'Callaghan AM, Mead GM. Chylothorax in lymphoma: mechanisms and management. Ann Oncol 1995; 6: 603 - 7.

28. Fogli L, Gorini P, Belcastro S. Conservative management of traumatic chylothorax: A case report. Intensive Care Med. 1993;19:176-7.

29. Browse NL, Allen DR, Wilson NM. Management of chylothorax. Br J Surg. 1997; 84: 1711-6. 